$\underline{\text { Review Article }}$

\title{
RECENT TRENDS IN MANAGEMENT OF KERATOCONJUNCTIVITIS SICCA (DRY EYE DISEASE)
}

\author{
NITHISH SHEKAR ${ }^{1}$, D. V. GOWDA ${ }^{1}$, HITESH KUMAR ${ }^{1}$, GAURAV K. JAIN², VIKAS JAIN ${ }^{1 *}$
}

${ }^{1}$ Department of Pharmaceutics, JSS College of Pharmacy, JSS Academy of Higher Education and Research, Mysuru, India, ${ }^{2}$ Department of Pharmaceutics, School of Pharmaceutical Education and Research, Jamia Hamdard, New Delhi India

Email: vikasjain@jssuni.edu.in

Received: 01 Jun 2019, Revised and Accepted: 11 Oct 2019

\begin{abstract}
At the air-water interface, the tear film lipid layer (TFLL), a combination of lipids and proteins plays an important role in surface tension of the tear and is necessary for the physiological hydration of the ocular surface and maintenance of ocular homeostasis. Alteration in lacrimal fluid rheology, differences in lipid constitution or down regulation of particular tear proteins are found in maximum types of ocular surface disease including dry eye disease (DED). Dry eye is a disorder of the tear film due to tear deficiency or excessive tear evaporation, which causes damage to the interpalpebral ocular surface and is associated with symptoms of discomfort. It results in changes on the ocular surface epithelia causing reduced tear quantity and surface sensitivity which leads to inflammation reactions. Managing this inflammation is very helpful in dry eye disease patients. In this article we revise the current understanding of tear film properties, ocular surface and review the effectiveness of topically applied tear supplements, thermo sensitive atelocollagen punctal plug, subtrasal ultrasonic transducers, novel liposome based gelling tear formation and insulin based ophthalmic delivery systems which help in restoring the healthy tear film.
\end{abstract}

Keywords: Evaporative dry eye (EDE), Keeptar, Aqueous tear deficient dry eye (ADDE), Tear break up time (TBUT)

(C) 2019 The Authors. Published by Innovare Academic Sciences Pvt Ltd. This is an open access article under the CC BY license (http://creativecommons.org/licenses/by/4.0/) DOI: http://dx.doi.org/10.22159/ijap.2019v11i6.36114

\section{INTRODUCTION}

Dry eye syndrome is a multifactorial disease affecting lacrimal gland and ocular surface causing discomfort, blurring of vision, instability of the tear film and with latent destruction of the ocular surface. It is often accompanied by increased osmolarity of the tefilm and inflammation of the ocular surface. Dry eye disease is categorized into aqueous-deficient (equating with reduced lacrimal gland function) and evaporative (equating very largely with meibomian gland dysfunction) dry eye disease. Evaporative dry eye is prevalent than aqueous-deficient dry eye, and patients develop both the form concomitantly [1]. The dry eye disease is a condition characterized by dryness in eye which causes an uncomfortable feeling and worsens over time. In 2014, dry eye was prevalent in $11 \%$ of the population in Spain where $11.9 \%$ of women and $9 \%$ of men were affected. Dry eye disease occurs due to decreased tear secretion, reduction in volume of tear on corneal surface as well as conjunctiva surface and increased evaporation of tear also causes dryness of eye $[2,3]$.

The exocrine gland continuously produces aqueous fluid which helps in maintaining the wetness on the ocular surface and is adjusted by blinking rate and environmental factors. [4]. Irritation in the eye also increases the tear secretion. The polymodal-nociceptor and mechan-o-receptor nerve endings are sensitive to irritants and thus detects and responds to the stimuli [5].

Clinical features of dry eye disease include eye fatigue feeling, keratoconjunctival epithelial disorder, dryness, ocular discomfort, hyperemia and abnormalities in vision. Dry eye disease is caused due to increased usage of VDT (video display terminal in television, personnel computer monitors), ageing, irritants, vitamin A insufficiency, rheumatologic disease, chemical and thermal burns, rheumatoid arthritis and also due to drugs such as levoblastin, oxybutynin, atenolol, levofloxacin, hydrochlorothiazide.

Treatment of dry eye disease

\section{Cyclosporine A}

Cyclosporine A was one of the first treatment for dry eye disease. It has shown the property to reduce the inflammation in the ocular surface and also targets the symptoms of dry eye disease. $0.05 \%$ and
$0.1 \%$ concentrations of Cyclosporine $\mathrm{A}$ are the appropriate concentrations used in treatment of dry eye disease.

A study was carried out to study the safety and efficacy of topically administered $0.05 \%$ cyclosporine $\mathrm{A}$ twice a day for the treatment of severe to moderate dry eye. The study showed improvement in the dry eye condition with time [6]. Sjoren Syndrome also leads to dry eye condition, the condition of which can be treated by Cyclosporine. It inhibits the cytokine receptors and reduces the inflammation thus aids in treating dry eye disease [7].

Ophthalmic emulsion of cyclosporine A was used to carry out study on dry eye syndrome for over 6 mo. The result was increase in number of goblet cells among the patients. The patients with or without systemic studies showed improvement in dry eye disease [8-10]. Thus $0.05 \%$ cyclosporine was patient compliant as it showed improved results within 3 to $6 \mathrm{mo}$.

\section{Hydroxypropyl cellulose ophthalmic inserts}

Opthalmic insert is a solid or semisolid consistency device placed into the cul-de-sac or conjuctival sac which is thin, multi-layered, drugimbued and most importantly sterile. The shape and size of the ocular inserts are specifically crafted for ophthalmic drug delivery. Inserts are mainly constituted by polymers with or without any medicament [11] The core objective of the ocular inserts is to enhance the residence time as well as the contact time between the formulation and the conjunctival tissue in order to provide a sustained release suitable for the treatment either topically or systemically. Ophthalmic inserts are an alternative treatment option applicable in the treatment of moderate-to-severe dry eye syndrome [12-14].

The ophthalmic inserts are the means of ophthalmic drug delivery system that need to be sterile. They are in the form of translucent rods measuring $1.27 \mathrm{~mm}$ in diameter and $3.5 \mathrm{~mm}$ in length. Each ophthalmic insert consists of $5 \mathrm{mg}$ hydroxypropyl cellulose, without any preservative and other excipients. The insert is administered into the eye by placing it into the inferior cul de sac cavity of the eye underneath the base of the tarsus, not in opposition to the cornea, nor beneath the eyelid at the level of the tarsal plate. The mechanism of action of Hydroxypropyl cellulose ocular inserts is by stabilizing and thickening the tear film and extending tear film breakup time (TBUT). In addition, it also lubricates and protects the eye. 


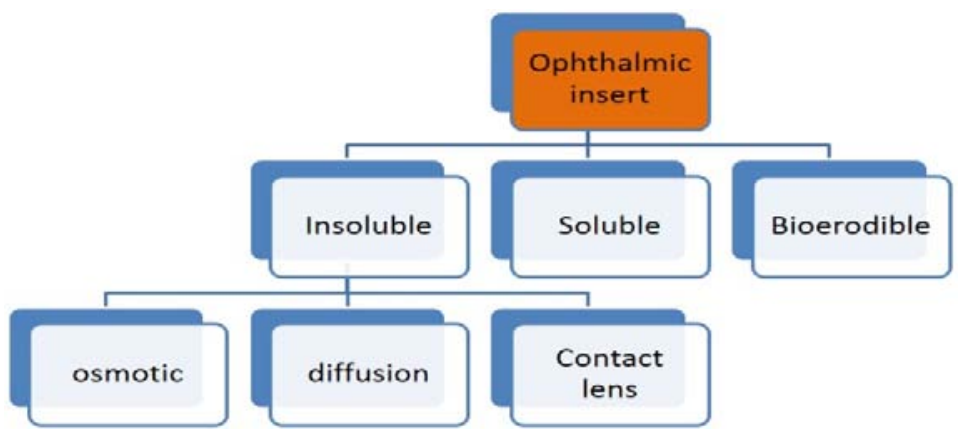

Fig. 1: Classification of ocular inserts

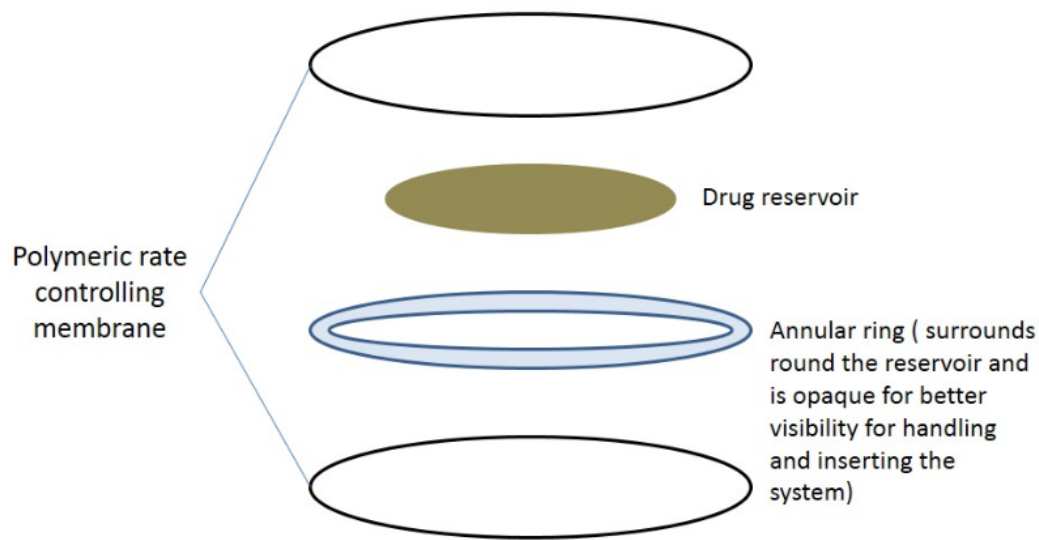

Fig. 2: Structural components of ocular inserts

The ocular inserts are designed particularly for the patients who possess dry eye indications even after a sufficient therapy with the use of artificial tears. The inserts can also be administered by the patients suffering from keratoconjunctivitis sicca, exposure keratitis, decreased corneal sensitivity, and recurrent corneal erosions. Hypersensitivity reactions to Hydroxypropyl cellulose is the only drawback of this therapy [15]

\section{Hyaluronic acid based eye drops}

The three layers on the preocular tear film are the outer tear film lipid layer, clear tear film aqueous layer and inner tear film mucin layer $[16,17]$. Hyaluronic acid has a viscoelastic rheology and is an anionic glycosaminoglycan mostly found in aqueous humor and vitreous humor. Hyaluronic acid based eye drops are coated around the corneal endothelium since it offers a lubricating effect and also offers resistance to dehydration, effectively binds to water and has good biocompatibility $[18,19]$. Artificial tear eye drops of HA can be used to stabilize the preocular tear film, improve the irregularity on the ocular surface and reduce the symptoms of dry eye [20-22]. A study was done to compare the efficacy of preservative free $0.1 \%$ $\mathrm{HA}, 0.18 \% \mathrm{HA}$ and $0.3 \% \mathrm{HA}$ artificial tear drops in the mouse model withering stress induced environmental and pharmacological experiment in dry eye disease. It displayed better protection of corneal epithelial cells compared to HPMC and CMC [23] and also better lubricant property by retaining moisture and acted as reservoirs in slowly releasing water molecules [24].

The frequently employed test for examining the tear film abnormality is the measurement of tear break up time (TBUT). TBUT is the time interval between the end completion of blink and first break in tear film [25]. The TBUT upon administration of HA shows improved stability of the tear film, reduced evaporation and hyperosmolarity in the tear film due to the property of water retention by HA [26]. $0.3 \%$ of HA showed significant activity on TBUT when compared to 0.18 and $0.1 \%$ HA. The higher concentration of HA also exhibited better corneal surface healing [27]. The goblet size density in conjunctiva was high on administration of $0.3 \% \mathrm{HA}$ and $0.18 \% \mathrm{HA}$ compared to $0.1 \% \mathrm{HA}$. The inflammation on the ocular surfaces decreases with increase in the goblet size [28]. Thus $0.3 \% \mathrm{HA}$ was most effective when compared to $0.18 \%$ and $0.1 \% \mathrm{HA}$ in the treatment of dry eye disease.

\section{Thermosensitive atelocollagen punctal plug}

The punctual plug has shown positive effects in treatment of aqueous tear deficit dry eye disease like neurogenic dry eye which is caused due to photorefractive ketacomy and (LASIK), dry eye caused due to contact lenses [29-31]. The punctual plugs are categorized into absorbable and non-absorbable plugs. Absorbable plugs are used in the treatment of temporary dry eye disease. For example, post-LASIK dry eyes. It can also be used in evaluating non absorbable plugs. Collagen punctal plug is an example for absorbable plug and it shows similar effect silicone plugs [32, 33]. Non Absorbable plugs like Freeman plug is the frequently used non absorbable plug available in various sizes which helps in fitting into various dry eye treatments [34-36]. It offers high stability and safety but also has few problems such as corneal irritation, epithelial laceration, frequent extrusion and granules formation.

Thermosensitive atelocollagen punctal plug (Keeptear) is recently been developed and under usage in Japan. It is an absorbable plug available in syringe, liquid at room temperature which turns into gel at body temperature so as to fit well in the patient's punctum. It is to be injected in to the patient's canalicus from the punctum. The keeptear is kept out for $15 \mathrm{~min}$ after taking out of refrigerator before injection. The atelocollagen turns into liquid state in $7 \mathrm{~min}$ when heated to $43^{\circ} \mathrm{C}$ but the crystal structure collapsed, thus $41^{\circ} \mathrm{C}$ with 8 min of heating was chosen to be suitable preheating condition. Keeptear blocks the canaliculi and retains the volume of tear for about 1 mo. It offers drawbacks such as its inability to confirm the localization of the plug post insertion and temporary effect in relation to punctal occlusion. It is best suited for seasonal worsening of dry eye and postsurgical dry eye [37]. Complications such as blurred vision, irritation, pain, foreign body sensations were not 
found when Keeptear was used. Thus the Keeptear was found to be safe and effective.

\section{Subtarsal ultrasonic transducers for mild hyperthermia treatment}

Meibomian glands are sebaceous glands present in upper and lower eye lids present 20 to 25 in numbers [38]. They secrete meibum which constitutes the lipid part of the tear that act as hydrophobic seal [39]. The secretion slows down the evaporation rate and increases the film stability. The meibomian lipid is present in liquid form in $36{ }^{\circ} \mathrm{C}$ [40]. But in patients with meibomian gland dysfunction, the meibum is secreted with abnormal elevated temperature by $3{ }^{\circ} \mathrm{C}$ to $4{ }^{\circ} \mathrm{C}$. This condition affects the secretion of meibomain lipid from meibomian ducts [41].

A recent study was conducted on the design and practicability of ultrasound device in mild hyperthermia in tarsal plate. The temperature of meibomian glands present in inner eyelid is increased by the device to the melting point of abnormal meibomian lipid assumed to be $41^{\circ} \mathrm{C}$ to $43^{\circ} \mathrm{C}$. The treatment last for 5 to $15 \mathrm{~min}$. The frequency of the treatment depends on the severity of the patient.

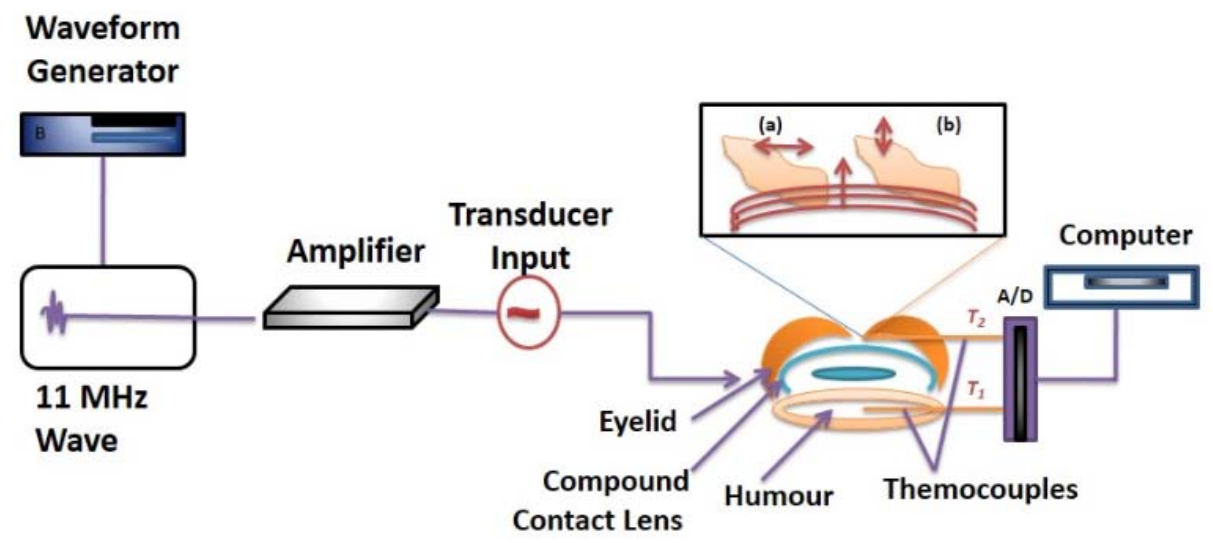

Fig. 3: Experimental design for hyperthermia experiments conducted in vivo. T1 and T2 indicates the temperatures of the humor and eyelid, which is measured by thermocouples embedded in the tissue

The hyperthermia therapy conducted for obstructive meibomian gland dysfunction is by liquefying the keratinized meibum present in meibomian gland thus elevating the temperature of glands by $5{ }^{\circ} \mathrm{C}$ to $7{ }^{\circ} \mathrm{C}\left(41{ }^{\circ} \mathrm{C}\right.$ to $\left.43{ }^{\circ} \mathrm{C}\right)$. This leads to secretion of meibum with increased stability and it avoids to evaporation of the tear from the ocular surface. This is due to its hydrophobic coat formation [42]. The heat induced is directly applied or effected to meibomian gland which is present at the Centre of inferior and the superior eyelid. Even though the diffusion of heat occurs by itself, more studies are required to know the spatial distribution of heat [43]

\section{Design of ultrasonic transducer}

The contact lens is embedded with piezo-electric transducers where an air gap is present internally. The air gap helps in providing the transducers with air backing. The transducers are fixed reflexively onto the posterior tarsal face. The acoustic waves gets reflected towards tarsus and then reflected away from cornea which prevents the cornea from heating due to direct application of ultrasound [44].
A recent in vivo study was conducted on porcine subject where an equilibrium rise in temperature $\left(5^{\circ} \mathrm{C}\right.$ to $\left.8^{\circ} \mathrm{C}\right)$ was observed in 10 to $15 \mathrm{~min}$. It was also found that the perfusion rate of blood reduced with time. Not more than $2{ }^{\circ} \mathrm{C}$ rise was seen in the corneal temperature. No evidence of corneal damage was found in the experiments.

\section{Tear supplements}

Carboxymethyl cellulose-glycerin-castor oil (cCGC) depicted the greatest trend in reducing the inflammatory biomarkers. After $4 \mathrm{w}$ of treatment, $40 \%$ of the subjects showed positive response. By the use of $\mathrm{CMC}, 10 \%$ of the patients showed positive response while the use of HPG showed no positive response. The stress levels in induced cellular hyperosmolarity was significantly reduced in CGC formulation in cell models and animal models [45-47]. The test was conducted to check its effect in Sjoren Syndrome, allergic eye disease, amblyopia and glaucoma, thus treatment effect and responsive index was determined [48-50]

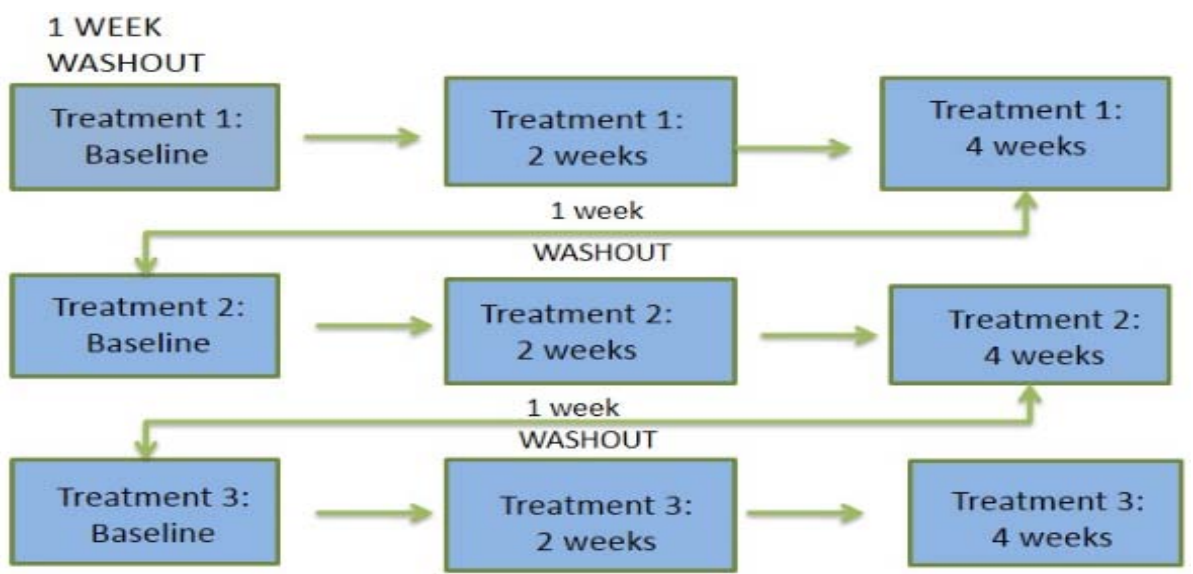

Fig. 4: Repeated measures study design. Each subject completed this program of visits with a 1 w washout duration before starting treatment 1 and a $1 \mathrm{w}$ washout between treatments 
A recent study was carried out on Interleukin 6 (IL-6) and matrix metallopeptidase 9 (MMP-9) levels in human with two artificial tears. It was found that the osmoprotectants and CMC reduced the inflammation levels [51, 52]. Castor oil upon instillation has reported the ocular residence time of $4 \mathrm{~h}[53,54]$. After the instillation of artificial tears, the treatment period must be prolonged for 2 to $4 \mathrm{w}$ in order to significantly affect the cytokine levels to reduce the inflammation. Compared to antiinflammatory medications, the osmoprotectants show rapid mechanism within $2 \mathrm{w}$ [55] However, longer duration of treatment has shown reduction in dry eye in murine model used in corneal staining and testing the goblet cell density [56].

The artificial tears are inclusive of preservatives. For example, CMC eye drops contained purite as preservative that causes the natural tear components to break down [57]. In animal model it shows very less epithelial erosion. Polyquad, a preservative used in HPG eye drops shows minimal effect in reducing the inflammation [58-60]

\section{Novel liposome-based and in-situ gels}

Restoring the tear film is one of the main objectives in treatment of dry eye disease. The novel artificial tear is formulated in such a way that it resembles the natural tear. Liposomes which contains phosphatidylcholine and cholesterol where used to restore the lipids in tear film. Gellan gum polymer has to feature of forming gel when it comes in contact with some ions which are present in the tear [6163]. This gel prevents the loss of tear and increase the resistance time of the formulation with the help of Hydroxyproply methyl cellulose (HPMC) which increases the bio-adhesion [64, 65]. To increase the effectiveness of artificial tears antioxidants like vitamin A and vitamin B, trehalose, osmoprotectants can be incorporated. The main physicochemical parameters to be considered include viscosity, $\mathrm{pH}$ and surface tension. Viscosity ranges from $1.0-8.3 \mathrm{mPas}$ $[66,67]$. If the viscosity increases then it might cause blurred vision, ocular discomfort and formulation instability due to non-uniform mixing with natural tears. The $\mathrm{pH}$ of human tear is 7.0 to 7.5 and due to the buffering capacity, the $\mathrm{pH}$ of the formulation can be adjusted accordingly as required to reduce the discomfort in eyes $[68,69]$. The surface tension of tears ranges between $40-46 \mathrm{mN} / \mathrm{m}[70,71]$. It is an important parameter to consider as it interacts with the tear film and could affect the spread on the ocular surface [72].

If all the above parameters are in proper levels (pH-7.6, viscosity$4 \mathrm{mPas}$, surface tension $-53.4 \mathrm{mN} / \mathrm{m}$ ) a good formulation can be developed. The liposomal nano-particles must also possess suitable size for formulation as artificial tears. The artificial tear did not show any toxic effects on both J774 and HeLa cell lines. It didn't cause any discomfort in the rabbits and showed better in vivo tolerance. The novel liposomal artificial tear showed a good potential to replenish the tear, protect the corneal epithelium and successfully treat the dry eye disease. Due to its gelling property it showed good property to develop as a formulation for ophthalmic administration.

\section{Prospective insulin based ophthalmic delivery systems}

Diabetes mellitus (DM) could be one of the reasons for dry eye disease condition because they lead to complications like diabetic retinopathy, cataract which leads to the alterations on ocular surface and affects the functioning of the lacrimal gland (LG) [73-75]. This condition leads to reduction in the volume of tear secretion due to the condition of diabetes mellitus the disruption on ocular surface will not be healed easily which leads to inflammation and dry eye syndrome [76, 77].
Insulin receptors are present on the ocular surface and the lacrimal gland thus this approach can be used for healing the corneal surface [78]. Application of insulin on the ocular surface topically is a good strategy but the drawback of this is the reduced resident time on the ocular surface because of mechanisms such as drug dilution, tearing and reduced bioavailability [79]. Invasive release systems can be used for administration of insulin through implants, aqueous solutions [80].

Micro particulate delivery systems show better drug delivery compared to the nanoparticles [81]. They are made to increase their resistance time on the ocular surface by incorporating them along with a in situ thermo reversible gel which stays in aqueous state where its viscosity will be same as the conventional eye drops in the room temperature and when it comes in contact with the ocular surface it turns into gel form. This gel increases the resistance time on the ocular surface and increases the mechanical strength and prevents the drug leakage [82].

Chitosan possess good biocompatibility, biodegradability, penetration and mucoadhesion which help in increasing the bioavailability. Thus, it can be used as polymer in preparation of microparticles. Opposite charges exists between insulin (negative) and chitosan (positive) [83], which helps in incorporating the insulin into the microparticles. Polyelectrolyte complexation is used to prepare the chitosan microspheres [84].

Incorporation of the insulin into the chitosan polymeric microparticles did not make significant difference in the size and morphology compared to conventional eye drop. The microparticles have micrometric size which prevents from blurring of vision [85]. No discomfort in the eye was observed. Thus insulin loaded chitosan microparticles where having optimum particle size and physiochemical characteristics to be used as topical ocular formulation.

\section{Diquafosol ophthalmic solution}

Diquafosol is a P2Y2 purinergic receptor antagonist. It is characterized by fluid secretion, increase in the mucin secretion due to gradual increase in goblet cells, increase in the hydrophilic characteristics on the ocular surface, strengthening of aqueous mucin layer, increase in the gene expression of membrane binding in corneal epithelial cells and tear film stabilization $[86,87]$. Diquafosol ophthalmic solution $(3 \% \mathrm{w} / \mathrm{v})$ on topical instillation show positive action towards both type of dry eye disease-aqueous tear deficient dry eye (ADDE) and evaporative dry eye (EDE). It effectively alleviates the symptoms and increases TFBUT among the patients with short TFBUT type dry eye where there is observation of decreased TFBUT and not much damage of epithelium and avoid the dysfunction of lacrimal gland is seen [88]. Application of diquafosol for about 1 mo showed the improvement in symptoms of dry eye, corneoconjunctival staining and TFBUT. Adverse reactions could be observed in $4.3 \%$ of patient's. [89]. Diquafosol can also be used in combination with $0.1 \%$ hyaluronic solution in formulation and it shows better tear stability thus can be used to treat dry eye.

Diaquafosol exhibits better efficacy in patients with short TFBUT type of dry eye caused by environmental stress, long usage of video display terminals like television and personal computers etc. [9092]. The results of test done on patients with dry eye disease using diquafosol $(3 \% \mathrm{w} / \mathrm{v})$ are shown in the table 1 .

Table 1: The percentage of patients who showed changes in dry eye symptoms and ocular signs after $4 \mathrm{w}$ of topical administration of $3 \%$ diquafosol ophthalmic solution

\begin{tabular}{llll}
\hline Changes after treatment in patients & \multicolumn{3}{l}{ No. of patients treated (\%) } \\
\cline { 2 - 4 } & Improved & No change & Worsened \\
\hline Subjective dry eye symptom & $55(78.6)$ & $15(21.4)$ & $0(0)$ \\
Tear film break-up time & $46(65.7)$ & $22(31.4)$ & $2(2.9)$ \\
Ocular staining score & $44(62.8)$ & $23(32.9)$ & $3(4.3)$ \\
\hline
\end{tabular}

\section{CONCLUSION}

Knowledge regarding tear film properties and ocular surface plays a key role in the treatment and management of dry eye disease. Tear drops, Hyaluronic acid eye drops, thermosensitive atelocollagen punctal plug, subtrasal ultrasonic transducers, novel liposome based gelling tear formation and insulin based ophthalmic delivery systems 
help in restoring the healthy tear film. $0.3 \%$ HA showed better effect that $0.18 \%$ HA and $0.1 \%$ HA. $0.05 \%$ Cyclosporine A twice a day for over 6 mo showed increase in goblet cells thus treating dry eye. Tear supplements like carboxymethyl cellulose-glycerin-castor oil (cCGC), carboxymethyl cellulose (CMC), Hydroxypropyl guar (HPG) showed positive results in treatment of dry eye disease. Thermosensitive atelocollagen punctal plug, Subtrasal ultrasonic transducers and novel liposome based in situ gelling tear formation showed good potential to replenish the tear, protect the corneal epithelium. 3\% diquafosol ophthalmic solution on topical instillation show positive action towards both the types of dry eye disease. Insulin loaded chitosan microparticles regulate the function of lacrimal gland. These available treatments have therefore led to improvements in detection and management of this common condition, which provides enormous benefits to the patients.

\section{AUTHORS CONTRIBUTIONS}

All authors have contributed equally

\section{CONFLICT OF INTERESTS}

The authors have no conflict of interest to declare

\section{REFERENCES}

1. Lemp MA, Crews LA, Bron AJ, Foulks GN, Sullivan BD. Distribution of aqueous-deficient and evaporative dry eye in a clinic-based patient cohort: a retrospective study. Cornea 2012;31:472-8

2. Moss SE, Klein R, Klein BE. Long-term incidence of dry eye in an older population. Optometry Vision Science 2008;85:668-74.

3. Barker KE, Savage NW. Burning mouth syndrome: an update on recent findings. Australian Dental J 2005;50:220-3.

4. Leiblum SR, Hayes RD, Wanser RA, Nelson JS. Vaginal dryness: a comparison of prevalence and interventions in 11 countries. J Sexual Med 2009;6:2425-33.

5. Acosta MC, Peral A, Luna C, Pintor J, Belmonte C, Gallar J. Tear secretion induced by selective stimulation of corneal and conjunctival sensory nerve fibers. Investigative Ophthalmol Visual Sci 2004;45:2333-6.

6. Stevenson D, Tauber J, Reis BL. Efficacy and safety of cyclosporin a ophthalmic emulsion in the treatment of moderate-to-severe dry eye disease: a dose-ranging, randomized trial. The cyclosporin a phase 2 study group. Ophthalmology 2000;107:967-74.

7. Kroemer G, Martinez C. Cytokines and autoimmune disease. Clin Immunol Immunopathol 1991;61:275-95.

8. Barber LD, Pflugfelder SC, Tauber J, Foulks GN. Phase III safety evaluation of cyclosporine $0.1 \%$ ophthalmic emulsion administered twice daily to dry eye disease patients for up to 3 y. Ophthalmology 2005;112:1790-4.

9. Sall K, Stevenson OD, Mundorf TK, Reis BL. Two multicenter, randomized studies of the efficacy and safety of cyclosporine ophthalmic emulsion in moderate to severe dry eye disease. CsA Phase 3 Study Group. Ophthalmology 2000;107:631-9.

10. Kujawa A, Rozycki R. A 0, 05\% cyclosporine treatment of the advanced dry eye syndrome. Klinika Oczna 2005;107:280-6.

11. Kumari A, Sharma PK, Garg VK, Garg G. Ocular insertsadvancement in therapy of eye diseases. J Adv Pharm Technol Res 2010;1:291.

12. Robinson JC. Ocular anatomy and physiology relevant to ocular drug delivery. Drugs Pharm Sci 1993;58:29-57.

13. Mitra AK. Ophthalmic drug delivery systems; 2003.

14. Chien YW. Nasal drug delivery and delivery systems. Novel Drug Delivery Systems (2nd ed.), Marcel Dekker, Inc., New York; 1992. p. 229-68.

15. Nguyen T, Latkany R. Review of hydroxypropyl cellulose ophthalmic inserts for treatment of dry eye. Clin Ophthalmol 2011;5:587.

16. Willcox MD, Argueso P, Georgiev GA, Holopainen JM, Laurie GW, Millar TJ, et al. TFOS DEWS II tear film report. Ocular Surface 2017;15:366-403.

17. Cher I. A new look at lubrication of the ocular surface: fluid mechanics behind the blinking eyelids. Ocular Surface 2008;6:79-86
18. Johnson ME, Murphy PJ, Boulton M. Effectiveness of sodium hyaluronate eyedrops in the treatment of dry eye. Graefe's Arch Clin Exp Ophthalmol 2006;244:109-12.

19. Nakamura M, Hikida M, Nakano T, Ito S, Hamano T, Kinoshita S. Characterization of water retentive properties of hyaluronan. Cornea 1993;12:433-6.

20. Oh HJ, Li Z, Park SH, Yoon KC. Effect of hypotonic $0.18 \%$ sodium hyaluronate eyedrops on inflammation of the ocular surface in experimental dry eye. J Ocular Pharmacol Ther 2014;30:53342.

21. Aragona P, Papa V, Micali A, Santocono M, Milazzo G. Long term treatment with sodium hyaluronate-containing artificial tears reduces ocular surface damage in patients with dry eye. $\mathrm{Br}$ J Ophthalmol 2002;86:181-4.

22. Lee HS, Ji YS, Yoon KC. Efficacy of hypotonic $0.18 \%$ sodium hyaluronate eye drops in patients with dry eye disease. Cornea 2014;33:946-51.

23. Li Y, Cui L, Lee HS, Kang YS, Choi W, Yoon KC. Comparison of $0.3 \%$ hypotonic and isotonic sodium hyaluronate eye drops in the treatment of experimental dry eye. Curr Eye Res 2017;42:1108-14.

24. Zheng X, Goto T, Shiraishi A, Ohashi Y. In vitro efficacy of ocular surface lubricants against dehydration. Cornea 2013;32:1260-4.

25. Wolffsohn JS, Arita R, Chalmers R, Djalilian A, Dogru M, Dumbleton K, et al. TFOS DEWS II diagnostic methodology report. Ocular Surface 2017;15:539-74.

26. Prabhasawat $P$, Tesavibul N, Kasetsuwan N. Performance profile of sodium hyaluronate in patients with lipid tear deficiency: randomised, double-blind, controlled, exploratory study. Br J Ophthalmol 2007;91:47-50.

27. Zhang $X$, Chen $W$, De Paiva CS, Corrales RM, Volpe EA, McClellan AJ, et al. Interferon- $\gamma$ exacerbates dry eye-induced apoptosis in conjunctiva through dual apoptotic pathways. Invest Ophthalmol Visual Sci 2011;52:6279-85.

28. Oh HJ, Li Z, Park SH, Yoon KC. Effect of hypotonic $0.18 \%$ sodium hyaluronate eyedrops on inflammation of the ocular surface in experimental dry eye. J Ocular Pharmacol Ther 2014;30:53342.

29. Sakamoto A, Kitagawa K, Tatami A. Efficacy and retention rate of two types of silicone punctal plugs in patients with and without Sjogren syndrome. Cornea 2004;23:249-54.

30. Giovagnoli D, Graham SJ. Inferior punctal occlusion with removable silicone punctal plugs in the treatment of dry-eye related contact lens discomfort. J Am Optometric Assoc 1992;63:481-5

31. Kaido M, Goto E, Dogru M, Tsubota K. Punctal occlusion in the management of chronic stevens-johnson syndrome. Ophthalmology 2004;111:895-900.

32. Hsu HC. Ampullary pyogenic granuloma as a complication of lacrimal plug migration. Migration 2002;2:6.

33. Nava Castaneda A, Tovilla Canales JL, Rodriguez L, Tovilla YPJL, Jones CE. Effects of lacrimal occlusion with collagen and silicone plugs on patients with conjunctivitis associated with dry eye. Cornea 2003;22:10-4.

34. Yung YH, Toda I, Sakai C, Yoshida A, Tsubota K. Punctal plugs for treatment of post-LASIK dry eye. Japanese J Ophthalmol 2012;56:208-13.

35. Kaido M, Ishida R, Dogru M, Tsubota K. Visual function changes after punctal occlusion with the treatment of short BUT type of dry eye. Cornea 2012;31:1009-13.

36. Sabti S, Halter JP, Fränkl BB, Goldblum D. Punctal occlusion is safe and efficient for the treatment of keratoconjunctivitis sicca in patients with ocular GvHD. Bone Marrow Transplantation 2012;47:981.

37. Ibrahim OM, Dogru M, Ward SK, Matsumoto Y, Wakamatsu TH, Ishida $\mathrm{K}$, et al. The efficacy, sensitivity, and specificity of strip meniscometry in conjunction with tear function tests in the assessment of tear meniscus. Invest Ophthalmol Visual Sci 2011;52:2194-8

38. Dutton JJ, Frueh BR. Eyelid anatomy and physiology with reference to blepharoptosis. In: Evaluation and management of blepharoptosis. Springer, New York, NY; 2011. p. 13-26.

39. Cher I. Fluids of the ocular surface: concepts, functions and physics. Clin Exp Ophthalmol 2012;40:634-43. 
40. Blackie CA, McMonnies CW, Korb DR. Warm compresses and the risks of elevated corneal temperature with massage. Cornea 2013;32:e146-9.

41. Nichols KK, Foulks GN, Bron AJ, Glasgow BJ, Dogru M, Tsubota $\mathrm{K}$, et al. The international workshop on meibomian gland dysfunction: executive summary. Invest Ophthalmol Visual Sci 2011;52:1922-9.

42. Waterman FM, Nerlinger RE, Leeper JB. Catheter induced temperature artifacts in ultrasound hyperthermia. Int J Hyperthermia 1990;6:371-81.

43. Wang H, Ritter T, Cao W, Shung KK. High frequency properties of passive materials for ultrasonic transducers. IEEE Transactions Ultrasonics Engineering 2001;48:78-84.

44. Olson MC, Korb DR, Greiner JV. Increase in tear film lipid layer thickness following treatment with warm compresses in patients with meibomian gland dysfunction. Eye Contact Lens 2003;29:96-9.

45. Corrales RM, Luo L, Chang EY, Pflugfelder SC. Effects of osmoprotectants on hyperosmolar stress in cultured human corneal epithelial cells. Cornea 2008;27:574-9.

46. X Hua, Z Su, R Deng, J Lin, DQ Li, SC Pflugfelder. Effects of 1carnitine, er-ythritol and betaine on pro-inflammatory markers in primary human corneal epi-thelial cells exposed to hyperosmotic stress. Curr Eye Res 2015;40:657-67.

47. She Y, Li J, Xiao B, Lu H, Liu H, Simmons PA, et al. Evaluation of a novel artificial tear in the prevention and treatment of dry eye in an animal model. J Ocular Pharmacol Ther 2015;31:52530.

48. Scheiman MM, Hertle RW, Beck RW, Edwards AR, Birch E, Cotter SA, et al. Randomized trial of treatment of amblyopia in children aged 7 to $17 \mathrm{y}$. Arch Ophthalmol 2005;123:437-47.

49. Woo DM, Healey PR, Graham SL, Goldberg I. Intraocular pressure-lowering medications and long-term outcomes of selective laser trabeculoplasty. Clin Exp Ophthalmol 2015;43:320-7.

50. Giede C, Metzenauer P, Petzold U, Ellers Lenz B. Comparison of azelastine eye drops with levocabastine eye drops in the treatment of seasonal allergic conjunctivitis. Curr Med Res Opin 2000;16:153-63.

51. Wolffsohn JS, Arita R, Chalmers R, Djalilian A, Dogru M, Dumbleton $\mathrm{K}$, et al. TFOS DEWS II diagnostic methodology report. Ocular Surface 2017;15:539-74.

52. Lanzini M, Curcio C, Colabelli Gisoldi RA, Mastropasqua A, Calienno R, Agnifili L, et al. In vivo and impression cytology study on the effect of compatible solutes eye drops on the ocular surface epithelial cell quality in dry eye patients. Mediators Inflammation 2015. http://dx.doi.org/10.1155/2015/351424

53. Occhipinti JR, Mosier MA, Lamotte J, Monji GT. Fluorophotometric measurement of human tear turnover rate. Curr Eye Res 1988;7:995-1000.

54. Maissa C, Guillon M, Simmons P, Vehige J. Effect of castor oil emulsion eyedrops on tear film composition and stability. Contact Lens Anterior Eye 2010;33:76-82.

55. She Y, Li J, Xiao B, Lu H, Liu H, Simmons PA, et al. Evaluation of a novel artificial tear in the prevention and treatment of dry eye in an animal model. J Ocular Pharmacol Ther 2015;31:52530.

56. Tomlinson A, Madden LC, Simmons PA. Effectiveness of dry eye therapy under conditions of environmental stress. Curr Eye Res 2013;38:229-36.

57. Noecker R. Effects of common ophthalmic preservatives on ocular health. Adv Ther 2001;18:205-15.

58. Paimela T, Ryhanen T, Kauppinen A, Marttila L, Salminen A, Kaarniranta K. The preservative polyquaternium-1 increases cytoxicity and NF-kappa B linked inflammation in human corneal epithelial cells. Mol Vision 2012;18:1189.

59. K Kinnunen, A Kauppinen, N Piippo, A Koistinen, E Toropainen, $\mathrm{K}$ Kaarniranta. Cationorm shows good tolerability on human HCE-2 corneal epithelial cell cultures. Exp Eye Res 2014;120:82-9.

60. Dutescu RM, Panfil C, Schrage N. Comparison of the effects of various lubricant eye drops on the in vitro rabbit corneal healing and toxicity. Exp Toxicol Pathol 2017;69:123-9.
61. Milas M, Shi X, Rinaudo M. On the physicochemical properties of gellan gum. Biopolymers: Original Res Biomolecules 1990;30:451-64

62. Matsukawa S, Watanabe T. Gelation mechanism and network structure of mixed solution of low-and high-acyl gellan studied by dynamic viscoelasticity, CD and NMR measurements. Food Hydrocolloids 2007;21:1355-61.

63. Chandrasekaran $\mathrm{R}$, Thailambal VG. The influence of calcium ions, acetate and L-glycerate groups on the gellan double-helix. Carbohydrate Polymers 1990;12:431-42.

64. Miyoshi E, Takaya T, Nishinari K. Rheological and thermal studies of gel-sol transition in gellan gum aqueous solutions. Carbohydrate Polymers 1996;30:109-19.

65. Kumar K, Dhawan N, Sharma H, Vaidya S, Vaidya B. Bioadhesive polymers: novel tool for drug delivery. Artif Cells Nanomed Biotechnol 2014;42:274-83.

66. Tiffany JM. The viscosity of human tears. Int Ophthalmol 1991;15:371-6.

67. Gouveia SM, Tiffany JM. Human tear viscosity: an interactive role for proteins and lipids. Biochim Biophys Acta 2005; 1753:155-63.

68. Abelson MB, Udell IJ, Weston JH. Normal human tear $\mathrm{pH}$ by direct measurement. Arch Ophthalmol 1981;99:301.

69. Yamada M, Mochizuki H, Kawai M, Yoshino M, Mashima Y. Fluorophotometric measurement of $\mathrm{pH}$ of human tears in vivo. Curr Eye Res 1997;16:482-6.

70. Miller D. Measurement of the surface tension of tears. Arch Ophthalmol 1969;82:368-71.

71. Nagyova B, Tiffany JM. Components responsible for the surface tension of human tears. Curr Eye Res 1999;19:4-11.

72. Han K, Woghiren OE, Priefer R. Surface tension examination of various liquid oral, nasal, and ophthalmic dosage forms. Chem Central J 2016;10:31.

73. Alves MD, Carvalheira JB, Modulo CM, Rocha EM. Tear film and ocular surface changes in diabetes mellitus. Arquivos Brasileiros De Oftalmologia 2008;71:96-103.

74. Vieira Potter VJ, Karamichos D, Lee DJ. Ocular complications of diabetes and therapeutic approaches. BioMed Res Int 2016. http://dx.doi.org/10.1155/2016/3801570

75. Zhang X, Zhao L, Deng S, Sun X, Wang N. Dry eye syndrome in patients with diabetes mellitus: prevalence, etiology, and clinical characteristics. J Ophthalmol 2016 http://dx.doi.org/10.1155/2016/8201053

76. Azar DT, Gipson IK. Repair of the corneal epithelial adhesion structures following keratectomy wounds in diabetic rabbits. Acta Ophthalmol 1989;67(S192):72-9.

77. DT Azar, SJ Spurr Michaud, AS Tisdale, IK Gipson. Altered epithelialbasement membrane interactions in diabetic corneas. Arch Ophthalmol 1992;110:537-40.

78. EM Rocha, AE Hirata, EM Carneiro, MJ Saad, LAJE Velloso. Impact of gender on insulin signaling pathway in lacrimal and salivary glands of rats. Endocrine 2002;18:191-9.

79. DA Cunha, EM Carneiro, M de C Alves, AG Jorge, SM de Sousa, AC Boschero, et al. Rocha, metabolism, insulin secretion by rat lacrimal glands: effects of systemic and local variables. Am J Physiol Endocrinol Metab 2005;289:E768-75.

80. Zagon IS, Sassani JW, McLaughlin PJ. Insulin treatment ameliorates impaired corneal reepithelialization in diabetic rats. Diabetes 2006;55:1141-7.

81. Gaudana R, Jwala J, Boddu SH, Mitra AK. Recent perspectives in ocular drug delivery. Pharm Res 2009;26:1197.

82. Gratieri T, Gelfuso GM, Rocha EM, Sarmento VH, de Freitas O, Lopez RF. A poloxamer/chitosan in situ forming gel with prolonged retention time for ocular delivery. Eur J Pharm Biopharm 2010;75:186-93.

83. Elsayed A, Al-Remawi M, Farouk A, Badwan A. Insulin-chitosan polyelectrolyte-anocomplexes: preparation, characterization and stabilization of insulin. Sudan J Med Sci 2010;5:99-109.

84. Varshousaz J, Alinagari R. Effect of citric acid as cross-linking agent on insulin loaded chitosan microspheres. Iranian Polymer J (English) 2005;14:647-56.

85. Choy YB, Park JH, Prausnitz MR. Mucoadhesive microparticles engineered for ophthalmic drug delivery. J Phys Chem Solids 2008;69:1533-6. 
86. Nakamura M, Imanaka T, Sakamoto A. Diquafosol ophthalmic solution for dry eye treatment. Adv Ther 2012;29:579-89.

87. Koh S. Clinical utility of $3 \%$ diquafosol ophthalmic solution in the treatment of dry eyes. Clin Ophthalmol (Auckland, NZ) $2015 ; 9: 865$.

88. Shimazaki Den S, Iseda H, Dogru M, Shimazaki J. Effects of diquafosol sodium eye drops on tear film stability in short BUT type of dry eye. Cornea 2013;32:1120-5.

89. Yamaguchi M, Nishijima T, Shimazaki J, Takamura E, Yokoi N, Watanabe $\mathrm{H}$, et al. Clinical usefulness of diquafosol for real-world dry eye patients: a prospective, open-label, non-interventional, observational study. Adv Ther 2014;31:1169-81.
90. Uchino M, Yokoi N, Uchino Y, Dogru M, Kawashima M, Komuro A, et al. Prevalence of dry eye disease and its risk factors in visual display terminal users: the Osaka study. Am J Ophthalmol 2013;156:759-66.

91. Yokoi N, Uchino M, Uchino Y, Dogru M, Kawashima M, Komuro A, et al. Importance of tear film instability in dry eye disease in office workers using visual display terminals: the Osaka study. Am J Ophthalmol 2015;159:748-54.

92. Kojima T, Ibrahim OM, Wakamatsu T, Tsuyama A, Ogawa J Matsumoto $\mathrm{Y}$, et al. The impact of contact lens wear and visual display terminal work on ocular surface and tear functions in office workers. Am J Ophthalmol 2011;152:933-40. 